\title{
Prognostic Value of Quality of Life in Endocrine Therapy for Elderly Patients With Breast Cancer: A Retrospective Study
}

\author{
KOJI TAKADA ${ }^{1}$, SHINICHIRO KASHIWAGI ${ }^{1}$, YUKA ASANO $^{1}$, WATARU GOTO ${ }^{1}$, \\ KATSUYUKI TAKAHASHI ${ }^{2}$, MASATSUNE SHIBUTANI ${ }^{3}$, RYOSUKE AMANO ${ }^{4}$, \\ TSUTOMU TAKASHIMA ${ }^{1}$, SHUHEI TOMITA ${ }^{2}$, KOSEI HIRAKAWA ${ }^{1,3}$ and MASAICHI OHIRA ${ }^{1,3}$ \\ ${ }^{1}$ Department of Breast and Endocrine Surgery, Osaka City University Graduate School of Medicine, Osaka, Japan; \\ ${ }^{2}$ Department of Pharmacology, Osaka City University Graduate School of Medicine, Osaka, Japan; \\ ${ }^{3}$ Department of Gastrointestinal Surgery, Osaka City University Graduate School of Medicine, Osaka, Japan; \\ ${ }^{4}$ Department of Hepato-Biliary-Pancreatic Surgery, Osaka City University Graduate School of Medicine, Osaka, Japan
}

\begin{abstract}
Background: Several studies have established a positive relationship between quality of life $(Q O L)$ and prognosis in patients with various cancer types. This study investigated QOL of elderly patients with primary hormone receptor-positive breast cancer who chose endocrine therapy as their first-line treatment. Patients and Methods: $Q O L$ $A C D-B$ scores were evaluated before and after endocrine therapy for 75 patients. The results of the interviews were used to determine the Charlson Comorbidity Index. Results: In a univariate analysis, baseline objective response rate $(p=0.009)$, and increase in $Q O L(p=0.037)$ significantly correlated with longer progression-free survival time. There was a correlation between 3-month QOL score and longer overall survival in the multivariate analysis $(p=0.035)$. Conclusion: In elderly patients with breast cancer who underwent first-line endocrine therapy, improved QOL at 3 months after treatment initiation correlated with prolonged progression-free survival. High QOL scores were associated with prolonged overall survival.
\end{abstract}

Breast cancer incidence in the elderly has been increasing yearly. Owing to morbidities or poor performance status (PS), elderly patients are often ineligible for standard treatments. Moreover, patients or their families sometimes refuse guideline-recommended treatments. Surgery for breast cancer often requires general anesthesia, which may be

Correspondence to: Shinichiro Kashiwagi, MD, Ph. D., Department of Breast and Endocrine Surgery, Osaka City University Graduate School of Medicine, 1-4-3 Asahi-machi, Abeno-ku, Osaka 5458585, Japan. Tel: +81 666453838, Fax: +81 666466450, e-mail: spqv9ke9@view.ocn.ne.jp

Key Words: Quality of life, elderly patients, endocrine therapy, breast cancer, prognostic marker. contraindicated in patients in poor general condition. Chemotherapy can cause severe side-effects and exacerbate the patient's quality of life (QOL). According to previous reports, side-effects are more frequent in elderly patients than young patients, as are deaths due to treatment-related complications (1-3).

Once breast cancer has spread beyond the regional lymph nodes, complete recovery is difficult. The treatment objective then shifts from recovery to palliative care, with the goals of controlling symptoms, improving QOL, and prolonging overall survival (OS). In particular, when treating conditions that are non-life-threatening, it is important to select therapies that maintain QOL. Endocrine therapy (ET) causes milder adverse events than does chemotherapy, and is therefore often chosen in cases of hormone receptor-positive breast cancer (HRBC) (Hortobagyi's algorithm) (4).

Several studies have established a positive relationship between QOL and prognosis in patients with various cancer types (5-8). Other studies showed that early introduction of psychological care and palliative treatment improved both QOL and prognosis $(9,10)$. Hence, we hypothesized that even therapies that prioritize QOL rather than therapeutic responses will affect the prognosis of elderly patients with breast cancer. This study tested this hypothesis in elderly patients with primary HRBC who chose ET as their first-line treatment.

\section{Materials and Methods}

Patient background. Our study targeted patients with primary HRBC who were aged $\geq 65$ years at diagnosis and who underwent first-line ET. There were 75 eligible patients from November 2007 to December 2017 at the Osaka City University Hospital (11). PS was evaluated at the first visit, and medical history was examined via interviews (Table I) (12). Patients with dementia who unable to answer medical history questions were excluded from the study. The results of the interviews were used to determine the Charlson 
Table I. Eastern Cooperative Oncology Group (ECOG) performance status scale.

\begin{tabular}{ll}
\hline Grade & ECOG performance status \\
\hline 0 & Fully active, able to carry on all pre-disease performance without restriction \\
1 & Restricted in physically strenuous activity but ambulatory and able to carry out work of a light or sedentary nature, \\
2 & e.g. light house work, office work \\
3 & Ambulatory and capable of all selfcare but unable to carry out any work activities; up and about more than 50\% of waking hours \\
4 & Capable of only limited selfcare; confined to bed or chair more than 50\% of waking hours \\
5 & Completely disabled; cannot carry on any selfcare; totally confined to bed or chair \\
\hline
\end{tabular}

Comorbidity Index (CCI), which predicts mortality by scoring each complication (Table II) (13).

All patients first underwent concurrent ultrasonography (US) and biopsy for tumor assessment. Breast cancer was pathologically diagnosed by examining biopsy tissue; expression of estrogen receptor, progesterone receptor, human epidermal growth factor receptor 2 (HER2), and Ki67 was determined via immunostaining. After diagnosis of breast cancer, computed tomography (CT) and bone scintigraphy were performed to evaluate the progression of the cancer. After completing all examinations, ET was started on an outpatient basis. Three months thereafter, therapeutic responses were assessed via physical examinations, US, and CT according to the Response Evaluation Criteria in Solid Tumors criteria (14).

Study outcomes. The objective response rate (ORR) was defined as the percentage of responders [i.e. patients with a clinical partial response (cPR) or a clinical complete response (cCR)]. Patients with clinical stable disease or progressive disease were considered nonresponders. All patients were followed-up with physical examinations every 3 months and US and CT every 6 months. Progression-free survival (PFS) was calculated from the date of treatment start to the date of disease progression or death. OS was calculated from the date of treatment start to the date of death. In cases in which there was no disease progression, the treatment was changed and subsequently discontinued. The median follow-up period was 784 days (range $=99-3163$ days).

QOL evaluation. In Japan, the Quality of Life Questionnaire for Cancer Patients Treated with Anticancer Drugs (QOL-ACD) is commonly used to assess QOL after general cancer treatments (Table III) (15). The QOL-ACD was developed by Kurihara et al. (15) and is supported by the Japanese Ministry of Health and Welfare. There are specific QOL scales for each type of cancer; for breast cancer, the QOL-ACD-breast (B) scale is used (16). Briefly, each item is evaluated on a scale from 1 to 5 , with 1 being the worst score and 5 being the best score. There are 18 items in all; items not applicable to a particular treatment or difficult to evaluate are treated as "no answer". The overall QOL score is calculated by subtracting 1 from the average score of the items and multiplying by 25 ; this results in overall scores from 0 to 100 . We retrospectively evaluated QOL on the day the patient decided to undergo ET and then at 3 months after ET began. The difference between the two scores was calculated. We also determined whether QOL affected prognosis.

Ethics statement. This study was conducted at the Osaka City University Graduate School of Medicine, Osaka, Japan, according to
Table II. Charlson Comorbidity Index (CCI) scoring system.

\begin{tabular}{ll}
\hline Score & Condition \\
\hline 1 & Myocardial infarction \\
& Congestive heart failure \\
& Peripheral vascular disease \\
& Cerebrovascular disease \\
& Dementia \\
& Chronic obstructive pulmonary disease \\
& Connective tissue disease \\
& Peptic ulcer disease \\
& Mild liver disease \\
& Diabetes mellitus \\
& Hemiplegia \\
& Moderate to severe chronic kidney disease \\
& Diabetes with end-organ damage \\
& Tumor without metastases \\
& Leukemia (acute or chronic) \\
& Malignant lymphoma \\
& Moderate or severe liver disease \\
& Metastatic solid tumor \\
& Acquired immune deficiency syndrome \\
\hline
\end{tabular}

For each decade above 40 years of age, a score of 1 is added to the above score.

the Reporting Recommendations for Tumor Marker Prognostic Studies guidelines and following a retrospectively written research, pathological evaluation, and statistical plan (17). The study protocol was approved by the Ethics Committee of Osaka City University (number 926). Written informed consent was obtained from all patients.

Statistical methods. Statistical analysis was performed using the JMP software package (SAS, Tokyo, Japan). Relationships between factors were examined using the chi-squared test. The KaplanMeier method and the log-rank test were used to assess the relationship between QOL and survival (PFS and OS). Hazard ratios (HRs) and 95\% confidence intervals were calculated using the Cox proportional hazards model. Multivariate analysis was performed using the Cox regression model. In order to stratify patients at high risk of malignancy-related recurrence, patients were divided into groups with high QOL and low QOL before treatment (baseline) and 3 months after treatment start. Cut-off values were determined via receiver operating characteristic (ROC) curve analysis. A value of $p<0.05$ was considered significant. 
A

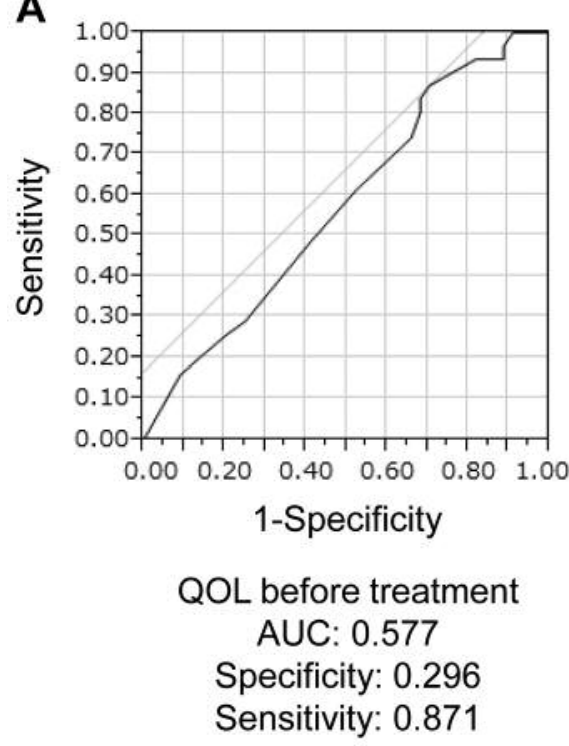

B

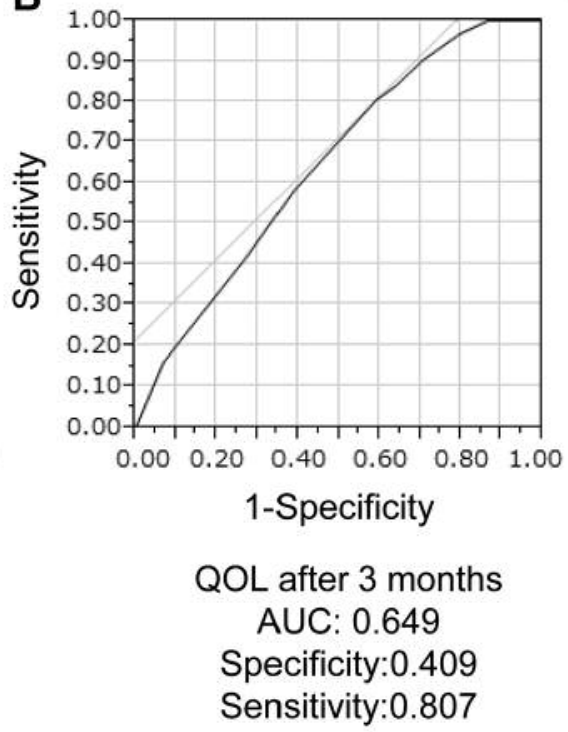

C

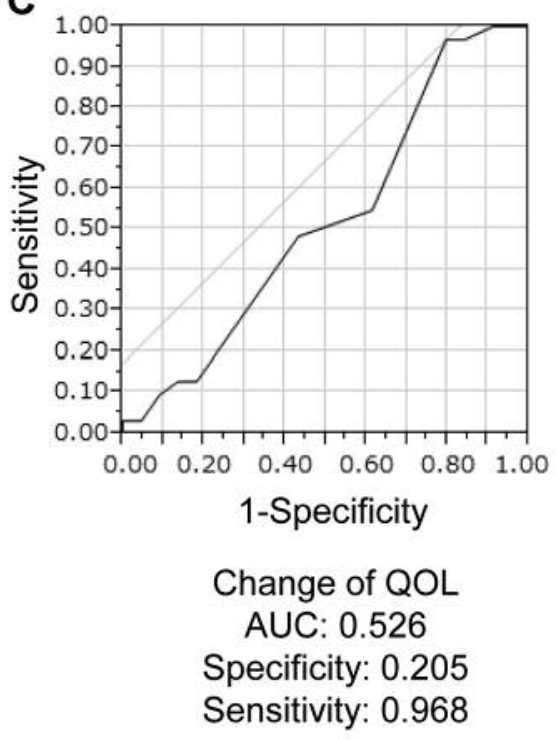

Figure 1. Receiver operating characteristic (ROC) curve analysis to determine cut-off values for quality of life (QOL). A: The cut-off value for the baseline $Q O L$ score was 85.94 [area under the curve $(A U C)=0.577$, sensitivity=87.1\%, specificity=29.6\%]. B: The cut-off value of 3-month QOL score was 93.75 (AUC=0.649, sensitivity=80.7\%, specificity=40.9\%). C: The cut-off value for change in QOL score after 3 months was 0 ( $A U C=0.526$, sensitivity $=96.8 \%$, specificity $=20.5 \%)$.

Table III. Quality of Life Questionnaire for Cancer Patients Treated with Anticancer Drugs-Breast (QOL-ACD-B).

Physical symptoms and pain

Did you have pain or numbness in the chest, armpits or arms of the disease side?

Did you have swollen arms (swollen) on the diseased side?

Were you able to raise the arm on the diseased side enough?

Were you concerned about the skin symptoms (redness, swelling, hotness, itching, etc.) around the chest on the diseased side?

Did you have any pain related to disease or treatment?

(Please answer this question only if you underwent surgery) Were you satisfied with the shape of your breasts and surgical scar?

Satisfaction with treatment and coping with disease

$7 \quad$ Were you satisfied with the explanation from your doctor about the medical condition and treatment?

Were you satisfied with the hospital facilities and non-doctor staff?

Did you adequately accept your disease?

10 Did you think about how you would face the disease?

Side-effects of treatment

11 Did you have hair loss?

12 Did you feel tired?

13 Did you suffer from hot flashes and sweating on your body and forehead?

14 Did you suffer from changes in taste (abnormalities)?

Dress, sexual aspect, other

15 Did you feel inconvenienced in clothes, such as you could not wear clothes you wanted to wear?

16 Did you feel hesitant about being naked in public, such as at a hot spring?

17 Are you satisfied with your sex life?

18 Were you concerned that your family would get the same disease? 
Table IV. Clinical features of 75 patients with primary hormone receptor-positive breast cancer.

\begin{tabular}{|c|c|c|}
\hline \multicolumn{2}{|l|}{ Parameter $(n=75)$} & \multirow{2}{*}{$\begin{array}{c}\begin{array}{c}\text { Number of } \\
\text { patients }(\%)\end{array} \\
77(65-102)\end{array}$} \\
\hline Age, years & Median (range) & \\
\hline \multirow[t]{7}{*}{ CCI, n (\%) } & 2 & $16(21.3 \%)$ \\
\hline & 3 & $16(21.3 \%)$ \\
\hline & 4 & $10(13.4 \%)$ \\
\hline & 5 & $3(4.0 \%)$ \\
\hline & 6 & $14(18.7 \%)$ \\
\hline & 7 & $9(12.0 \%)$ \\
\hline & 8 & $7(9.3 \%)$ \\
\hline \multirow[t]{5}{*}{ ECOG PS, n (\%) } & 0 & $54(72.0 \%)$ \\
\hline & 1 & $8(10.7 \%)$ \\
\hline & 2 & $5(6.7 \%)$ \\
\hline & 3 & $6(8.0 \%)$ \\
\hline & 4 & $2(2.6 \%)$ \\
\hline Tumor size, mm & Median (range) & $36.8(13.2-95.0)$ \\
\hline \multirow[t]{2}{*}{ Skin infiltration, n (\%) } & Negative & $30(40.0 \%)$ \\
\hline & Positive & $45(60.0 \%)$ \\
\hline \multirow{4}{*}{$\begin{array}{l}\text { Lymph node metastasis, } \\
\text { n }(\%)\end{array}$} & No & $26(34.7 \%)$ \\
\hline & N1 & $14(18.6 \%)$ \\
\hline & $\mathrm{N} 2$ & $20(26.7 \%)$ \\
\hline & $\mathrm{N} 3$ & $15(20.0 \%)$ \\
\hline \multirow{4}{*}{$\begin{array}{l}\text { Number of organs with } \\
\text { distant metastasis, } \mathrm{n}(\%)\end{array}$} & 0 & $49(65.3 \%)$ \\
\hline & 1 & $12(16.0 \%)$ \\
\hline & 2 & $9(12.0 \%)$ \\
\hline & 3 & $5(6.7 \%)$ \\
\hline \multirow{4}{*}{$\begin{array}{l}\text { Site of metastases } \\
(\mathrm{n}=45), \mathrm{n}(\%)\end{array}$} & Bone & $20(44.4 \%)$ \\
\hline & Lung & $13(28.9 \%)$ \\
\hline & Liver & $3(6.7 \%)$ \\
\hline & Distant lymph node & $9(20.0 \%)$ \\
\hline \multirow[t]{2}{*}{ Ki-67 } & Negative & $43(57.3 \%)$ \\
\hline & Positive & $32(42.7 \%)$ \\
\hline \multirow[t]{6}{*}{ First ET } & Letrozole & $43(57.3 \%)$ \\
\hline & Anastrozole & $22(29.3 \%)$ \\
\hline & Tamoxifen & $4(5.4 \%)$ \\
\hline & Exemestane & $4(5.4 \%)$ \\
\hline & LH-RH agonist+tamoxifen & $1(1.3 \%)$ \\
\hline & Toremifen & $1(1.3 \%)$ \\
\hline \multirow{4}{*}{$\begin{array}{l}\text { ORR after } 3 \text { months } \\
\text { from start of treatment } \\
\text { ORR }\end{array}$} & Non-responders & $42(56.0 \%)$ \\
\hline & Responders & $33(44.0 \%)$ \\
\hline & Non-responders & $25(33.3 \%)$ \\
\hline & Responders & $50(66.7 \%)$ \\
\hline \multirow{4}{*}{$\begin{array}{l}\text { Median QOL score } \\
\text { (range) }\end{array}$} & Before treatment (baseline) & ) 92.19 \\
\hline & & $(56.25-98.44)$ \\
\hline & At 3 months after treatment & tt $\quad 93.75$ \\
\hline & & $(62.50-98.44)$ \\
\hline Change in QOL after & Median (range) & 1.56 \\
\hline 3 months' ET & & $(-21.88-18.75)$ \\
\hline
\end{tabular}

CCI: Charlson Comorbidity Index; ECOG PS: Eastern Cooperative Oncology Group performance status; ET: endocrine therapy; LH-RH: luteinizing hormone-releasing hormone; ORR: objective response rate; QOL: quality of life; QOL-ACD-B: Questionnaire for Cancer Patients Treated with Anti-Cancer Drugs-Breast.

\section{Results}

Clinicopathological features. The clinicopathological features of the 75 patients with primary HRBC in our study are listed in Table IV. All patients were $\geq 65$ years of age; the oldest patient was 102 years old, and the median age was 77 years. All patients were women except one. The median CCI was 4 (range $=2-6)$. The PS was 1 or more in $21(28 \%)$ patients. Twenty-three patients $(30.7 \%)$ underwent ET despite having resectable breast cancer. Among these patients, 11 refused surgery, six were unable to tolerate surgery owing to poor general condition, and six prioritized the treatment of other diseases.

The median tumor diameter was $36.8 \mathrm{~mm}$ (range $=13.2$ $95.0 \mathrm{~mm})$. Forty-five patients $(60.0 \%)$ had skin infiltration, 49 (65.3\%) had lymph node metastasis, and $26(34.7 \%)$ had distant metastasis, with bone as the most frequent site. All patients with bone metastasis received zoledronic acid or denosumab in combination with ET. Although tumors in two patients expressed HER2, they did not receive anti-HER2 therapy. None of patients received radiation therapy. Thirtythree patients $(44.0 \%)$ had a cPR at 3 months after treatment start, and during the course of ET, a total of 55 patients (66.7\%) had a cPR. No patient had a cCR. ET was modified or canceled in 44 patients $(58.7 \%)$ owing to disease progression (43 patients) or treatment priorities (one patient). Nine patients (12.0\%) died of breast cancer, and four (5.3\%) died of other diseases.

The median baseline QOL score was 92.19 (range $=56.25$ 98.44), and the cut-off value was 85.94 [area under the curve (AUC) $=0.577$, sensitivity $=87.1 \%$, specificity $=29.6 \%$ ] (Figure 1). The median 3-month QOL score was 93.75 (range $=62.50$ 98.44), and the cut-off value was 93.75 [AUC $=0.649$, sensitivity $=80.7 \%$, specificity $=40.9 \%]$. Hence, the median and cut-off values were equivalent. The median difference in the baseline versus 3-month QOL score was 1.56 (range $=-21.88$ 18.75), and the cut-off value was 0 [AUC $=0.526$, sensitivity $=96.8 \%$, specificity $=20.5 \%$ ]. Patients whose QOL score was higher at 3 months than at baseline were placed in the group with increased QOL, whereas those whose QOL score was lower at 3 months than at baseline or did not change were placed in the group with decreased QOL.

Correlations between clinical features and $Q O L$. Tumor size was larger in patients with low baseline $(p<0.001)$ and 3-month ( $p=0.029)$ QOL scores (Table V). Skin infiltration $(p<0.001)$ and lymph node metastasis $(p=0.010)$ were more frequent before treatment in the group with low QOL. At the 3-month follow-up, there was no correlation between skin infiltration or lymph node metastasis and QOL. QOL improvement more often occurred in patients with low baseline QOL score ( $p=0.014)$; however, at 3 months, more patients had a low QOL score $(p<0.001)$. PS was better in 


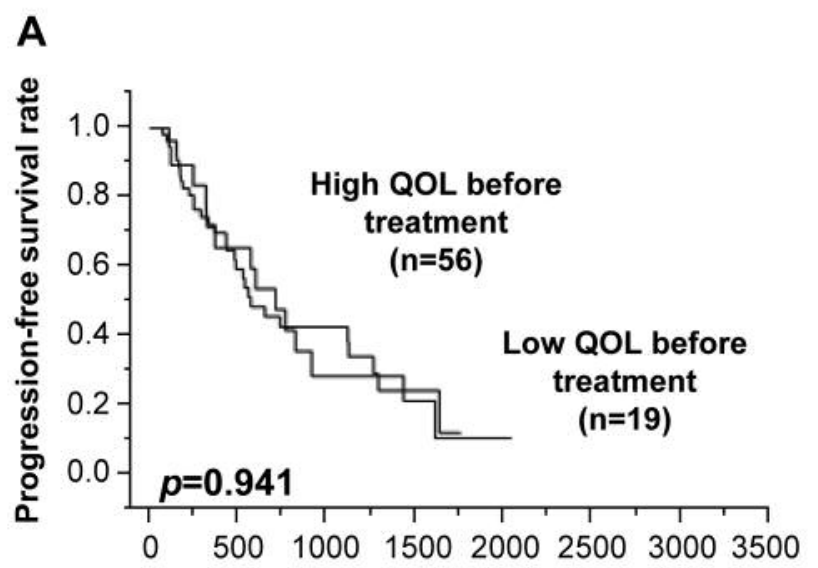

Days after treatment

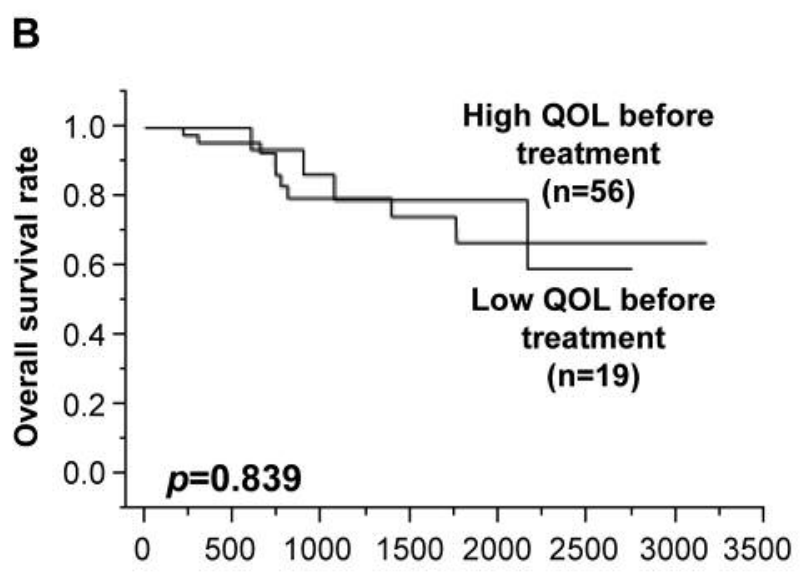

Days after treatment

Figure 2. Progression-free survival (PFS) (A) and overall survival $(O S)(B)$ in breast cancer according to baseline quality of life $(Q O L)$ score $(Q O L$ $A C D-B$ before treatment). Baseline QOL was not significantly associated with either PFS ( $p=0.941, \log$-rank) or OS ( $p=0.839, \log$-rank).
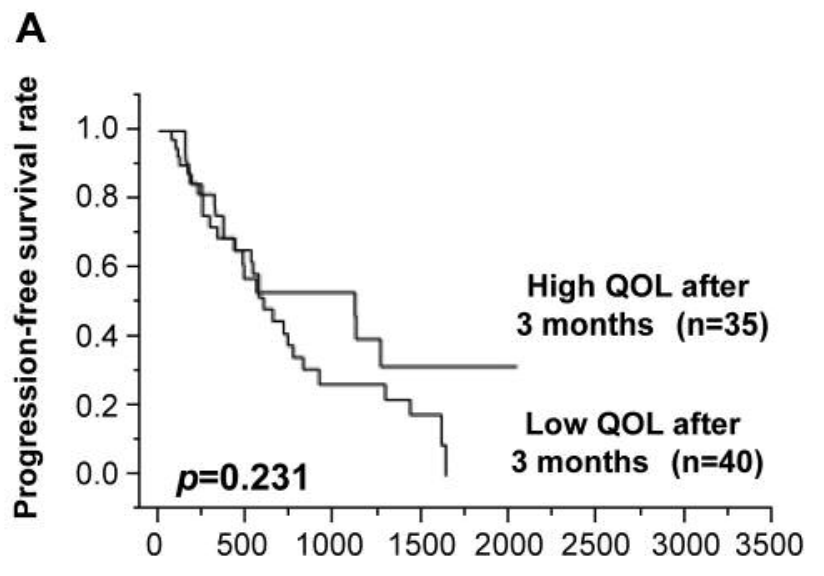

Days after treatment
B

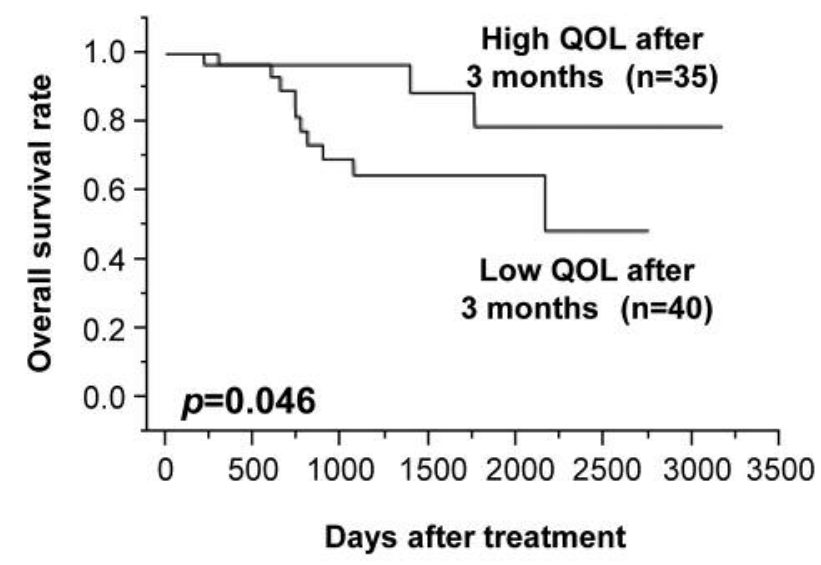

Figure 3. Progression-free survival (PFS) (A) and overall survival (OS) (B) in breast cancer according to quality of life (QOL) group at 3 months after treatment. Patients whose QOL score was higher at 3 months than at baseline were placed in the group with increased QOL, whereas those whose QOL score was lower at 3 months than at baseline or did not change were placed in the group with decreased QOL. There was no difference in PFS in 3-month QOL scores ( $p=0.231$, log-rank). The patients with high 3-month QOL scores had a significantly higher OS rate than did those with low 3-month QOL scores ( $p=0.046$, log-rank).

the group in which QOL increased rather than decreased $(p=0.001)$, as was the $\operatorname{ORR}(p=0.001)$.

Association of QOL with PFS and OS. Baseline QOL was not significantly associated with either PFS $(p=0.941)$ or OS $(p=0.839)$ (log-rank test) (Figure 2). However, patients with high 3-month QOL scores had a significantly higher OS rate than did those with low 3-month QOL scores ( $p=0.046$, logrank test) (Figure 3). Furthermore, the group with increased QOL had a significantly higher PFS rate than did that in which QOL decreased ( $p=0.029, \log$-rank test) (Figure 4$)$. In a univariate analysis, age $(p=0.003, \mathrm{HR}=0.398)$, baseline ORR $(p=0.009, \mathrm{HR}=0.404)$, and increase in QOL $(p=0.037$, $\mathrm{HR}=0.504)$ significantly correlated with longer PFS time (Table VI). Other clinical features such as PS and CCI were not associated with PFS. In a multivariate analysis, only age $(p<0.001, \mathrm{HR}=0.314)$ independently predicted PFS. There was no correlation between clinical features and age (Table VII). There was, however, a correlation between 3-month QOL score and longer OS time in the univariate $(p=0.041$, $\mathrm{HR}=0.291)$ and multivariate $(p=0.035, \mathrm{HR}=0.269)$ analysis (Table VIII). 
Table V. Correlation between clinical features and quality of life $(Q O L)$. Patients whose QOL score was higher at 3 months than at baseline were placed in the group with increased QOL, whereas those whose QOL score was lower at 3 months than at baseline or did not change were placed in the group with decreased $Q O L$.

\begin{tabular}{|c|c|c|c|c|c|c|c|c|c|}
\hline \multirow[t]{2}{*}{ Parameter } & \multicolumn{3}{|c|}{ QOL before treatment, $\mathrm{n}(\%)$} & \multicolumn{2}{|c|}{ QOL after 3 months, $\mathrm{n}(\%)$} & \multicolumn{4}{|c|}{ Change in QOL, n (\%) } \\
\hline & High $(n=56)$ & Low $(n=19)$ & $p$-Value & High $(n=35)$ & Low $(n=40)$ & $p$-Value & Increased $(n=44)$ & Decreased $(n=31)$ & $p$-Value \\
\hline \multicolumn{10}{|l|}{ Age (years) } \\
\hline$\leq 77$ & $27(48.2 \%)$ & $12(63.2 \%)$ & \multirow[t]{2}{*}{0.266} & $14(40.0 \%)$ & $25(62.5 \%)$ & \multirow[t]{2}{*}{0.053} & $23(52.3 \%)$ & $16(51.6 \%)$ & \multirow[t]{2}{*}{0.956} \\
\hline$>77$ & $29(51.8 \%)$ & $7(36.8 \%)$ & & $21(60.0 \%)$ & $15(37.5 \%)$ & & $21(47.7 \%)$ & $15(48.4 \%)$ & \\
\hline \multicolumn{10}{|l|}{ CCI } \\
\hline$\leq 4$ & $32(57.1 \%)$ & $10(52.6 \%)$ & \multirow[t]{2}{*}{0.736} & $20(57.1 \%)$ & $22(55.0 \%)$ & \multirow[t]{2}{*}{0.855} & $23(52.3 \%)$ & $19(61.3 \%)$ & \multirow[t]{2}{*}{0.445} \\
\hline$>4$ & $24(42.9 \%)$ & $9(47.4 \%)$ & & $15(42.8 \%)$ & $18(45.0 \%)$ & & $21(47.7 \%)$ & $12(38.7 \%)$ & \\
\hline \multicolumn{10}{|l|}{ ECOG PS } \\
\hline 0 & $40(71.4 \%)$ & $14(73.7 \%)$ & \multirow[t]{2}{*}{0.852} & $26(74.3 \%)$ & $28(70.0 \%)$ & \multirow[t]{2}{*}{0.685} & $38(86.4 \%)$ & $16(51.6 \%)$ & \multirow[t]{2}{*}{0.001} \\
\hline $1,2,3$ & $16(28.6 \%)$ & $5(26.3 \%)$ & & $9(25.7 \%)$ & $12(30.0 \%)$ & & $6(13.6 \%)$ & $15(48.4 \%)$ & \\
\hline \multicolumn{10}{|l|}{ Tumor size (mm) } \\
\hline$\leq 36.8$ & $35(62.5 \%)$ & $2(10.5 \%)$ & \multirow[t]{2}{*}{$<0.001$} & $22(62.9 \%)$ & $15(37.5 \%)$ & \multirow[t]{2}{*}{0.029} & $18(40.9 \%)$ & $19(61.3 \%)$ & \multirow[t]{2}{*}{0.084} \\
\hline$>36.8$ & $21(37.5 \%)$ & $17(89.5 \%)$ & & $13(37.1 \%)$ & $25(62.5 \%)$ & & $26(59.1 \%)$ & $12(38.7 \%)$ & \\
\hline \multicolumn{10}{|l|}{ Skin infiltration } \\
\hline Negative & $29(51.8 \%)$ & $1(5.3 \%)$ & \multirow[t]{2}{*}{$<0.001$} & $18(51.4 \%)$ & $12(30.0 \%)$ & \multirow[t]{2}{*}{0.060} & $14(31.8 \%)$ & $16(51.6 \%)$ & \multirow[t]{2}{*}{0.087} \\
\hline Positive & $27(48.2 \%)$ & $18(94.7 \%)$ & & $17(48.6 \%)$ & $28(70.0 \%)$ & & $30(68.2 \%)$ & $15(48.4 \%)$ & \\
\hline Ki67 & & & & & & & & & \\
\hline Negative & $30(53.6 \%)$ & $13(68.4 \%)$ & 0.264 & $17(48.6 \%)$ & $26(65.0 \%)$ & 0.075 & $29(65.9 \%)$ & $14(45.2 \%)$ & 0.155 \\
\hline Positive & $26(46.4 \%)$ & $6(31.6 \%)$ & & $18(51.4 \%)$ & $14(35.0 \%)$ & & $15(34.1 \%)$ & $17(54.8 \%)$ & \\
\hline Lymph node meta & & & & & & & & & \\
\hline Negative & $24(42.9 \%)$ & $2(10.5 \%)$ & 0.010 & $14(40.0 \%)$ & $12(30.0 \%)$ & 0.717 & $16(36.4 \%)$ & $10(32.3 \%)$ & 0.371 \\
\hline Positive & $32(57.1 \%)$ & $17(89.5 \%)$ & & $21(60.0 \%)$ & $28(70.0 \%)$ & & $28(63.6 \%)$ & $21(67.7 \%)$ & \\
\hline Distant metastasis & & & & & & & & & \\
\hline Negative & $39(30.4 \%)$ & $10(52.6 \%)$ & 0.183 & $23(65.7 \%)$ & $26(65.0 \%)$ & 0.949 & $28(63.6 \%)$ & $21(67.7 \%)$ & 0.717 \\
\hline Positive & $17(69.6 \%)$ & $9(47.4 \%)$ & & $12(34.3 \%)$ & $14(35.0 \%)$ & & $16(36.4 \%)$ & $10(32.3 \%)$ & \\
\hline ORR after 3 mont & & & & & & & & & \\
\hline Non-responders & $33(58.9 \%)$ & $9(47.4 \%)$ & 0.387 & $16(45.7 \%)$ & $26(65.0 \%)$ & 0.096 & $18(40.9 \%)$ & $24(77.4 \%)$ & 0.001 \\
\hline Responders & $23(41.1 \%)$ & $10(52.6 \%)$ & & $19(54.3 \%)$ & $14(35.0 \%)$ & & $26(59.1 \%)$ & $7(22.6 \%)$ & \\
\hline ORR & & & & & & & & & \\
\hline Non-responders & $20(35.7 \%)$ & $5(26.3 \%)$ & 0.460 & $8(22.9 \%)$ & $17(42.5 \%)$ & 0.074 & $8(18.2 \%)$ & $17(54.8 \%)$ & 0.001 \\
\hline Responders & $36(64.3 \%)$ & $14(73.7 \%)$ & & $27(77.1 \%)$ & $23(57.5 \%)$ & & $36(81.8 \%)$ & $14(45.2 \%)$ & \\
\hline Baseline QOL sco & & & & & & & & & \\
\hline Low & - & - & & $1(2.9 \%)$ & $18(45.0 \%)$ & $<0.001$ & $16(36.4 \%)$ & $3(9.7 \%)$ & 0.014 \\
\hline High & - & - & & $34(97.1 \%)$ & $22(55.0 \%)$ & & $28(63.6 \%)$ & $28(90.3 \%)$ & \\
\hline Change in QOL & & & & & & & & & \\
\hline Decrease & $28(50.0 \%)$ & $3(15.8 \%)$ & 0.014 & $16(45.7 \%)$ & $15(37.5 \%)$ & 0.471 & - & - & \\
\hline Increase & $28(50.0 \%)$ & $16(84.2 \%)$ & & $19(54.3 \%)$ & $25(62.5 \%)$ & & - & - & \\
\hline 3-Month QOL sco & & & & & & & & & \\
\hline Low & $22(39.3 \%)$ & $18(94.7 \%)$ & $<0.001$ & - & - & & $25(56.8 \%)$ & $15(48.4 \%)$ & 0.471 \\
\hline High & $34(60.7 \%)$ & $1(5.3 \%)$ & & - & - & & $19(43.2 \%)$ & $16(51.6 \%)$ & \\
\hline
\end{tabular}

CCI: Charlson Comorbidity Index; ECOG PS: Eastern Cooperative Oncology Group performance status; ORR: overall response rate.

\section{Discussion}

Elderly patients with cancer often choose non-standard treatments because they are sufferring complications $(18$, 19). Complications are difficult to evaluate; to do so, we used the CCI, although it is not the original method. Whereas some reports link complications to poor prognosis in patients with breast cancer $(18,19)$, others do not $(20)$. This discrepancy may largely reflect the method used to evaluate complications and whether the complications determined the treatment strategy. We believe that complications did not affect prognosis in our study because our study was retrospective and all treatments were the same.

The group with low QOL in the present study, as well as our previous study (21), had advanced local progression before treatment. Breast cancer occurs in a location that allows its presence to be felt from the outside; hence, patients are more often aware of breast cancer than of other types of 

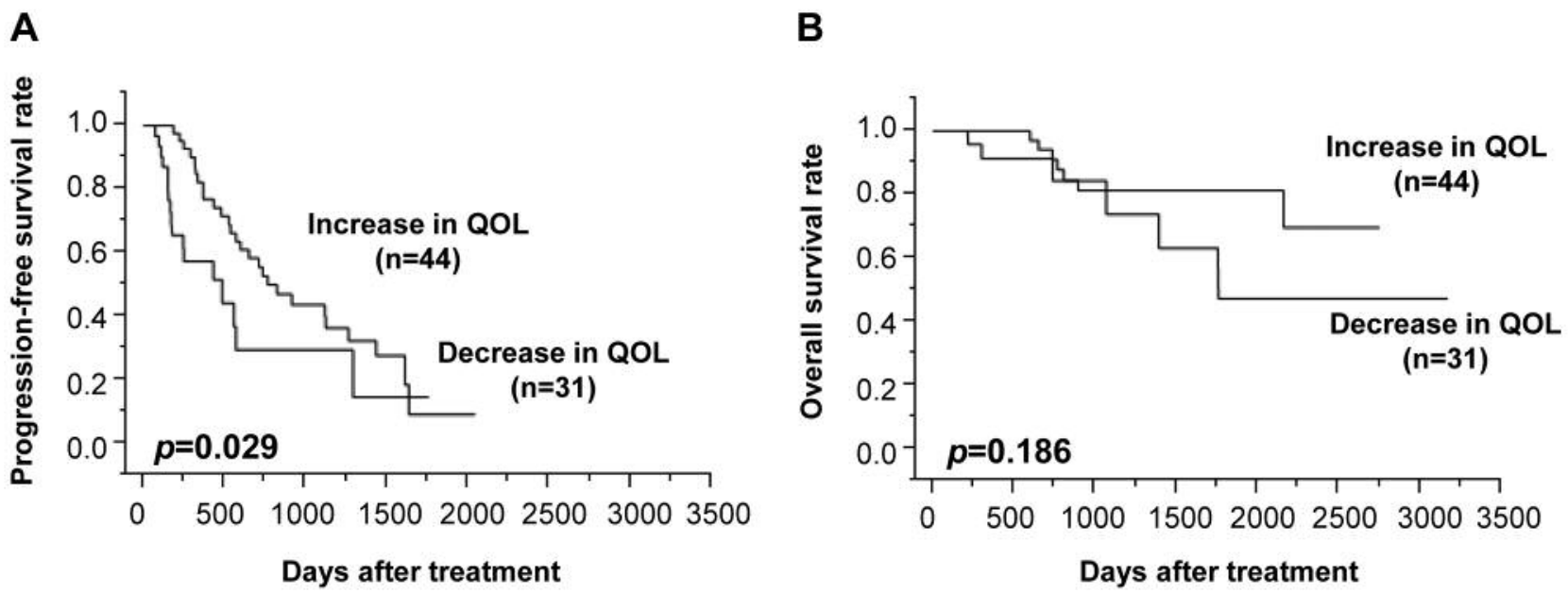

Figure 4. Progression-free survival (PFS) (A) and overall survival $(O S)(B)$ in breast cancer according to change in quality of life (QOL) (3 months after treatment). The group with increased QOL had a significantly higher PFS rate than did that for which QOL decreased ( $p=0.029$, log-rank). There was no difference in OS between the two groups ( $p=0.186$, log-rank).

Table VI. Univariate and multivariate analyses with respect to progression-free survival.

\begin{tabular}{|c|c|c|c|c|c|c|c|}
\hline \multirow[b]{2}{*}{ Parameter } & \multirow[b]{2}{*}{ Comparison } & \multicolumn{3}{|c|}{ Univariate analysis } & \multicolumn{3}{|c|}{ Multivariate analysis } \\
\hline & & HR & $95 \% \mathrm{CI}$ & $p$-Value & HR & $95 \% \mathrm{CI}$ & $p$-Value \\
\hline Age at treatment & $>77$ Years $(v s . \leq 77)$ & 0.398 & $0.210-0.730$ & 0.003 & 0.314 & $0.159-0.598$ & $<0.001$ \\
\hline CCI & $>4(v s . \leq 4)$ & 0.800 & $0.434-1.450$ & 0.462 & & & \\
\hline ECOG PS & $1,2,3,4(v s .0)$ & 1.848 & $0.960-3.413$ & 0.065 & 1.285 & $0.551-2.963$ & 0.558 \\
\hline Tumor size & $>36.8 \mathrm{~mm}(v s . \leq 36.8)$ & 0.890 & $0.490-1.634$ & 0.704 & & & \\
\hline Skin infiltration & Positive (vs. negative) & 0.710 & $0.391-1.309$ & 0.267 & & & \\
\hline Ki-67 & Positive ( $v s$. negative) & 1.646 & $0.870-3.065$ & 0.123 & & & \\
\hline Lymph node metastasis & Positive ( $v s$. negative) & 1.467 & $0.767-2.992$ & 0.253 & & & \\
\hline Distant metastasis & Positive (vs. negative) & 1.220 & $0.657-2.214$ & 0.521 & & & \\
\hline ORR ( 3 months after treatment) & Responders ( $v s$. non-responders) & 0.802 & $0.439-1.458$ & 0.469 & & & \\
\hline ORR & Responders (vs. non-responders) & 0.404 & $0.215-0.789$ & 0.009 & 0.505 & $0.227-1.147$ & 0.102 \\
\hline Baseline QOL score & High (vs. low) & 0.976 & $0.525-1.906$ & 0.941 & & & \\
\hline 3-Month QOL score & $\operatorname{High}(v s$. low $)$ & 0.691 & $0.369-1.259$ & 0.229 & & & \\
\hline Change in QOL & Increase ( $v s$. decrease) & 0.504 & $0.272-0.959$ & 0.037 & 0.532 & $0.262-1.112$ & 0.092 \\
\hline
\end{tabular}

CCI: Charlson Comorbidity Index; CI: confidence interval; ECOG PS: Eastern Cooperative Oncology Group performance status; HR: hazard ratio; ORR: overall response rate; QOL: quality of life; QOL-ACD-B: Questionnaire for Cancer Patients Treated with Anti-Cancer Drugs-Breast. Patients whose QOL score was higher at 3 months than at baseline were placed in the group with increased QOL, whereas those whose QOL score was lower at 3 months than at baseline or did not change were placed in the group with decreased QOL.

cancer. Because breast cancer symptoms usually appear at an early stage, the physical aspects of QOL tend to worsen early on. However, many patients with relatively early-stage breast cancer do not seek aggressive treatments or feel uneasy about the disease; i.e. they have a low psychological QOL but not a low physical QOL. Nevertheless, there is a recognized correlation between low baseline QOL and local druseprogression, because QOL scores are largely based on physical rather than psychological parameters. ET has few side-effects and thus is one of the treatments selected when considering QOL (4). In our study, QOL increased in over half of the patients after starting ET. However, because ET does not produce remarkable therapeutic effects early on, tumor size was unchanged 3 months after treatment start despite QOL improvement.

In our univariate analysis, PFS correlated with age, the ORR, and increase in QOL; however, in our multivariate analysis, age was the only independent prognostic factor. Some reports suggest that breast cancer prognosis in the elderly is the same as, or better than that in younger patients 
(22-24). Oddly, there is a significant difference in prognosis between older and younger members of elderly populations. Among patients who undergo image assessments on a regular basis, disease progression usually accounts for treatment changes. However, because the older patients in elderly populations have few treatment options, evaluation of therapeutic responses may be not very rigorous, thus allowing continuation of the same treatment.

Previous studies reported that QOL before treatment affected prognosis, as did changes in QOL over a 3-month treatment period $(25,26)$. Therefore, our present study also evaluated QOL 3 months after treatment initiation. QOL before treatment had no effect on prognosis, whereas QOL improvement at 3 months correlated with longer PFS. This result apparently reflected the strong association between improved QOL and higher ORR. Although changes in QOL did not affect OS, both QOL at 3 months and PS directly correlated with OS.

Previous multivariate analyses identified appetite loss and pain as independent predictors of OS in patients with breast cancer (26-29). In our study, we analyzed the association between several clinicopathological factors and OS; no significant associations were found (data not shown). Although some reports tentatively linked PS to various symptoms and prognosis $(25,27-29)$, our study found no clear correlation between PS and QOL at 3 months. It did, however, establish a correlation between OS and QOL at 3 months. Our findings support another report showing that QOL is a more sensitive prognostic factor than PS (6).

The limitation of this study is the retrospective (and thus perhaps imprecise) evaluation of QOL. Despite this limitation, we believe that our study shows the usefulness of QOL evaluation at 3 months after treatment initiation, as it may allow predictions of prognosis to be made after only a short amount of time. When treating breast cancer in the elderly, it is important to maintain QOL, as well as to obtain a favorable therapeutic response.

\section{Conclusion}

In elderly patients with breast cancer who underwent firstline ET, improved QOL at 3 months after treatment initiation correlated with prolonged PFS. High QOL scores at this time were associated with prolonged OS.

\section{Conflicts of Interest}

All Authors have no conflicts of interest to disclose in regard to this study.

\section{Authors' Contributions}

All Authors were involved in the preparation of this article. KoT collected the data, and wrote the article. SK, YA, WG and TT
Table VII. Correlation between clinical features and age.

\begin{tabular}{|c|c|c|c|}
\hline \multirow[b]{2}{*}{ Parameter } & \multicolumn{2}{|c|}{ Age } & \multirow[b]{2}{*}{$p$-Value } \\
\hline & $\begin{array}{c}\leq 77 \text { Years } \\
(\mathrm{n}=39)\end{array}$ & $\begin{array}{c}>77 \text { Years } \\
\quad(\mathrm{n}=36)\end{array}$ & \\
\hline \multicolumn{4}{|l|}{$\mathrm{CCI}$} \\
\hline$\leq 4$ & $19(48.7 \%)$ & $23(63.9 \%)$ & 0.191 \\
\hline$>4$ & $20(51.3 \%)$ & $13(36.1 \%)$ & \\
\hline \multicolumn{4}{|l|}{ ECOG PS } \\
\hline 0 & $29(74.4 \%)$ & $25(69.4 \%)$ & 0.641 \\
\hline $1,2,3,4$ & $10(25.6 \%)$ & $11(30.6 \%)$ & \\
\hline \multicolumn{4}{|l|}{ Tumor size } \\
\hline$\leq 36.8$ & $18(46.2 \%)$ & $19(52.8 \%)$ & 0.573 \\
\hline$>36.8 \mathrm{~mm}$ & $21(53.8 \%)$ & $17(47.2 \%)$ & \\
\hline \multicolumn{4}{|l|}{ Skin infiltration } \\
\hline Negative & $16(41.0 \%)$ & $14(38.9 \%)$ & 0.853 \\
\hline Positive & $23(59.0 \%)$ & $22(61.1 \%)$ & \\
\hline \multicolumn{4}{|l|}{ Ki67 } \\
\hline Negative & $21(53.8 \%)$ & $22(61.1 \%)$ & 0.532 \\
\hline Positive & $18(46.2 \%)$ & $14(38.9 \%)$ & \\
\hline \multicolumn{4}{|l|}{ Lymph node status } \\
\hline Negative & $10(25.6 \%)$ & $16(44.4 \%)$ & 0.090 \\
\hline Positive & $29(74.4 \%)$ & $20(55.6 \%)$ & \\
\hline \multicolumn{4}{|l|}{ Distant metastasis } \\
\hline Negative & $23(59.0 \%)$ & $26(72.2 \%)$ & 0.234 \\
\hline Positive & $16(41.0 \%)$ & $10(27.8 \%)$ & \\
\hline \multicolumn{4}{|c|}{ ORR after 3 months } \\
\hline Non-responders & $22(56.4 \%)$ & $20(55.6 \%)$ & 0.942 \\
\hline Responders & $17(43.6 \%)$ & $16(44.4 \%)$ & \\
\hline \multicolumn{4}{|l|}{ ORR } \\
\hline Non-responders & $16(41.0 \%)$ & $9(25.0 \%)$ & 0.145 \\
\hline Responders & $23(59.0 \%)$ & $27(75.0 \%)$ & \\
\hline \multicolumn{4}{|c|}{ Baseline QOL score } \\
\hline Low & $12(30.8 \%)$ & $7(19.4 \%)$ & 0.266 \\
\hline High & $27(69.2 \%)$ & $29(80.6 \%)$ & \\
\hline \multicolumn{4}{|c|}{ 3-Month QOL score } \\
\hline Low & $25(64.1 \%)$ & $15(41.7 \%)$ & 0.053 \\
\hline High & $14(35.9 \%)$ & $21(58.3 \%)$ & \\
\hline \multicolumn{4}{|l|}{ Change in QOL } \\
\hline Decrease & $16(41.0 \%)$ & $15(41.7 \%)$ & 0.956 \\
\hline Increase & $23(59.0 \%)$ & $21(58.3 \%)$ & \\
\hline
\end{tabular}

CI: Charlson Comorbidity Index; ECOG PS: Eastern Cooperative Oncology Group performance status; ORR: overall response rate. QOL: quality of life. Patients whose QOL score was higher at 3 months than at baseline were placed in the group with increased QOL, whereas those whose QOL score was lower at 3 months than at baseline or did not change were placed in the group with decreased QOL.

performed the operation and designed the study. KoT, KaT, MS and RA summarized the data, performed statistical analysis, and revised the article. TT, KH and MO substantial contribution to the study design, performed surgery, and revised the article. All Authors read and approved the final article.

Sources of support: This study was funded by grants from the Japan Society for the Promotion of Science (KAKENHI, Nos. 19K18067, 26461957, and 17K10559) to Shinichiro Kashiwagi. 
Table VIII. Univariate and multivariate analysis with respect to overall survival.

\begin{tabular}{|c|c|c|c|c|c|c|c|}
\hline \multirow[b]{2}{*}{ Parameter } & \multirow[b]{2}{*}{ Comparison } & \multicolumn{3}{|c|}{ Univariate analysis } & \multicolumn{3}{|c|}{ Multivariate analysis } \\
\hline & & $\mathrm{HR}$ & $95 \% \mathrm{CI}$ & $p$-Value & HR & $95 \% \mathrm{CI}$ & $p$-Value \\
\hline Age at treatment & $>77$ Years $(v s . \leq 77)$ & 0.589 & $0.177-1.781$ & 0.350 & & & \\
\hline $\mathrm{CCI}$ & $>4($ vs. $\leq 4)$ & 1.305 & $0.433-4.055$ & 0.632 & & & \\
\hline ECOG PS & $1,2,3,4(v s .0)$ & 4.663 & $1.467-14.403$ & 0.011 & 3.141 & $0.899-11.184$ & 0.072 \\
\hline Tumor size & $>36.8 \mathrm{~mm}(\mathrm{vs} . \leq 36.8)$ & 1.432 & $0.476-4.755$ & 0.526 & & & \\
\hline Skin infiltration & Positive ( $v s$. negative) & 1.107 & $0.369-3.672$ & 0.858 & & & \\
\hline Ki-67 & Positive ( $v s$. negative) & 1.262 & $0.381-3.790$ & 0.687 & & & \\
\hline Lymph node status & Positive ( $v s$. negative) & 1.734 & $0.528-7.754$ & 0.383 & & & \\
\hline Distant metastasis & Positive (vs. negative) & 1.273 & $0.409-3.843$ & 0.666 & & & \\
\hline ORR after 3 months & Responders ( $v s$. non-responders) & 0.330 & $0.088-1.029$ & 0.056 & 1.104 & $0.202-8.456$ & 0.912 \\
\hline ORR & Responders ( $v s$. non-responders) & 0.153 & $0.044-0.491$ & 0.002 & 0.182 & $0.026-0.804$ & 0.023 \\
\hline Baseline QOL score & High ( $v s$. low $)$ & 1.130 & $0.366-4.185$ & 0.838 & & & \\
\hline 3-Month QOL score & High (vs. low) & 0.485 & $0.161-1.513$ & 0.204 & & & \\
\hline Change in QOL & Increase ( $v s$. decrease) & 0.291 & $0.065-0.954$ & 0.041 & 0.269 & $0.058-0.914$ & 0.035 \\
\hline
\end{tabular}

CCI: Charlson Comorbidity Index; CI: confidence interval; ECOG PS: Eastern Cooperative Oncology Group performance status; HR: hazard ratio; ORR: overall response rate. QOL: quality of life. QOL-ACD-B: Questionnaire for Cancer Patients Treated with Anti-Cancer Drugs-Breast. Patients whose QOL score was higher at 3 months than at baseline were placed in the group with increased QOL, whereas those whose QOL score was lower at 3 months than at baseline or did not change were placed in the group with decreased QOL.

\section{Acknowledgements}

The Authors thank Yayoi Matsukiyo and Tomomi Okawa (Department of Breast and Endocrine Surgery, Osaka City University Graduate School of Medicine) for helpful advice regarding data management.

\section{References}

1 Cassidy J, Twelves C, Van Cutsem E, Hoff P, Bajetta E, Boyer M, Bugat R, Burger U, Garin A, Graeven U, McKendric J, Maroun J, Marshall J, Osterwalder B, Perez-Manga G, Rosso R, Rougier P, Schilsky RL and Capecitabine Colorectal Cancer Study Group: First-line oral capecitabine therapy in metastatic colorectal cancer: A favorable safety profile compared with intravenous 5-fluorouracil/leucovorin. Ann Oncol 13(4): 566575, 2002. PMID: 12056707. DOI: 10.1093/annonc/mdf089

2 Hurwitz N: Predisposing factors in adverse reactions to drugs. Br Med J 1(5643): 536-539, 1969. PMID: 5764700. DOI: $10.1136 / \mathrm{bmj} .1 .5643 .536$

3 Muss HB, Woolf S, Berry D, Cirrincione C, Weiss RB, Budman D, Wood WC, Henderson IC, Hudis C, Winer E, Cohen H, Wheeler J, Norton L, Cancer and Leukemia Group B: Adjuvant chemotherapy in older and younger women with lymph nodepositive breast cancer. JAMA 293(9): 1073-1081, 2005. PMID: 15741529. DOI: $10.1001 /$ jama.293.9.1073

4 Hortobagyi GN: Treatment of breast cancer. N Engl J Med 339(14): 974-984, 1998. PMID: 9753714. DOI: 10.1056/NEJM 199810013391407

5 Dancey J, Zee B, Osoba D, Whitehead M, Lu F, Kaizer L, Latreille $\mathrm{J}$ and Pater JL: Quality of life scores: An independent prognostic variable in a general population of cancer patients receiving chemotherapy. The National Cancer Institute of Canada Clinical Trials Group. Qual Life Res 6(2): 151-158, 1997. PMID: 9161115. DOI: 10.1023/A:1026442201191
6 Gotay CC, Kawamoto CT, Bottomley A and Efficace F: The prognostic significance of patient-reported outcomes in cancer clinical trials. J Clin Oncol 26(8): 1355-1363, 2008. PMID: 18227528. DOI: $10.1200 /$ JCO.2007.13.3439

7 Kaasa S, Mastekaasa A and Lund E: Prognostic factors for patients with inoperable non-small cell lung cancer, limited disease. The importance of patients' subjective experience of disease and psychosocial well-being. Radiother Oncol 15(3): 235-242, 1989. PMID: 2549582. DOI: 10.1016/0167-8140(89) 90091-1

8 Maisey NR, Norman A, Watson M, Allen MJ, Hill ME and Cunningham D: Baseline quality of life predicts survival in patients with advanced colorectal cancer. Eur J Cancer 38(10): 1351-1357, 2002. PMID: 12091066. DOI: 10.1016/S09598049(02)00098-9

9 Spiegel D, Bloom JR, Kraemer HC and Gottheil E: Effect of psychosocial treatment on survival of patients with metastatic breast cancer. Lancet 2(8668): 888-891, 1989. PMID: 2571815. DOI: 10.1016/S0140-6736(89)91551-1

10 Spiegel D, Sephton SE, Terr AI and Stites DP: Effects of psychosocial treatment in prolonging cancer survival may be mediated by neuroimmune pathways. Ann NY Acad Sci 840: 674-683, 1998. PMID: 9629294. DOI: 10.1111/j.17496632.1998.tb09606.x

11 Iimori N, Kashiwagi S, Asano Y, Goto W, Takada K, Takahashi K, Hatano T, Takashima T, Tomita S, Motomura H, Hirakawa K and Ohira M: Clinical significance of the neutrophil-tolymphocyte ratio in endocrine therapy for stage IV breast cancer. In Vivo 32(3): 669-675, 2018. PMID: 29695577. DOI: 10.21873/invivo.11292

12 Oken MM, Creech RH, Tormey DC, Horton J, Davis TE, McFadden ET and Carbone PP: Toxicity and response criteria of the Eastern Cooperative Oncology Group. Am J Clin Oncol 5(6): 649-655, 1982. PMID: 7165009. DOI: $10.1097 \% 2$ F00000421198212000-00014 
13 Charlson ME, Pompei P, Ales KL and MacKenzie CR: A new method of classifying prognostic comorbidity in longitudinal studies: Development and validation. J Chronic Dis 40(5): 373-383, 1987. PMID: 3558716. DOI: 10.1016/0021-9681(87)90171-8

14 Eisenhauer EA, Therasse P, Bogaerts J, Schwartz LH, Sargent D, Ford R, Dancey J, Arbuck S, Gwyther S, Mooney M, Rubinstein L, Shankar L, Dodd L, Kaplan R, Lacombe D and Verweij J: New response evaluation criteria in solid tumours: Revised RECIST guideline (version 1.1). Eur J Cancer 45(2): 228-247, 2009. PMID: 19097774. DOI: 10.1016/ j.ejca.2008. 10.026

15 Kurihara M, Shimizu H, Tsuboi K, Kobayashi K, Murakami M, Eguchi K and Shimozuma K: Development of quality of life questionnaire in japan: Quality of life assessment of cancer patients receiving chemotherapy. Psychooncology 8(4): 355-363, 1999. PMID: 10474853. DOI: 10.1002/(SICI)1099-1611(199907 /08)8:4<355::AID-PON401>3.0.CO;2-I

16 Otsuka S, Watanabe N, Sasaki $\mathrm{Y}$ and Shimojima R: Postoperative courses of breast reconstruction using inferior adipofascial tissue repair. Breast Cancer 22(6): 570-577, 2015. PMID: 24925523. DOI: 10.1007/s12282-014-0522-6

17 McShane LM, Altman DG, Sauerbrei W, Taube SE, Gion M, Clark GM and Statistics Subcommittee of the NCIEWGoCD: Reporting recommendations for tumor marker prognostic studies. J Clin Oncol 23(36): 9067-9072, 2005. PMID: 16106022. DOI: 10.1093/jnci/dji237

18 Yancik R, Wesley MN, Ries LA, Havlik RJ, Edwards BK and Yates JW: Effect of age and comorbidity in postmenopausal breast cancer patients aged 55 years and older. JAMA 285(7): 885-892, 2001. PMID: 11180731. DOI: 10.1001/jama.285.7.885

19 Bouchardy C, Rapiti E, Fioretta G, Laissue P, Neyroud-Caspar I, Schafer P, Kurtz J, Sappino AP and Vlastos G: Undertreatment strongly decreases prognosis of breast cancer in elderly women. J Clin Oncol 21(19): 3580-3587, 2003. PMID: 12913099. DOI: 10.1200/JCO.2003.02.046

20 Wolf I, Sadetzki S, Catane R, Karasik A and Kaufman B: Diabetes mellitus and breast cancer. Lancet Oncol 6(2): 103-111, 2005. PMID: 15683819. DOI: 10.1016/S1470-2045(05)01736-5

21 Takada K, Kashiwagi S, Goto W, Asano Y, Takahashi K, Morisaki T, Takashima T, Tomita S, Hirakawa K and Ohira M: Novel evaluation scale for QOL (QOL-ACD-BP) in preoperative chemotherapy for breast cancer. J Cancer Res Clin Oncol 144(8): 1547-1559, 2018. PMID: 29779135. DOI: 10.1007/s00432-0182670-0

22 Diab SG, Elledge RM and Clark GM: Tumor characteristics and clinical outcome of elderly women with breast cancer. J Natl Cancer Inst 92(7): 550-556, 2000. PMID: 10749910. DOI: $10.1093 /$ jnci/92.7.550
23 Singletary SE, Shallenberger R and Guinee VF: Breast cancer in the elderly. Ann Surg 218(5): 667-671, 1993. PMID: 8239782. DOI: $10.1097 / 00000658-199321850-00013$

24 Singh R, Hellman S and Heimann R: The natural history of breast carcinoma in the elderly: Implications for screening and treatment. Cancer 100(9): 1807-1813, 2004. PMID: 15112260. DOI: $10.1002 /$ cncr.20206

25 Shimozuma K, Sonoo H, Ichihara K and Tanaka K: The prognostic value of quality-of-life scores: Preliminary results of an analysis of patients with breast cancer. Surg Today 30(3): 255-261, 2000. PMID: 10752779. DOI: 10.1007/s005950050055

26 Efficace F, Biganzoli L, Piccart M, Coens C, Van Steen K, Cufer T, Coleman RE, Calvert HA, Gamucci T, Twelves C, Fargeot P and Bottomley A; EORTC-BCG-IDBBC-NDDG: Baseline health-related quality-of-life data as prognostic factors in a phase III multicentre study of women with metastatic breast cancer. Eur J Cancer 4O(7): 1021-1030, 2004. PMID: 15093577. DOI: 10.1016/j.ejca.2004.01.014

27 Lee CK, Stockler MR, Coates AS, Gebski V, Lord SJ, Simes RJ and Australian New Zealand Breast Cancer Trials Group: Selfreported health-related quality of life is an independent predictor of chemotherapy treatment benefit and toxicity in women with advanced breast cancer. Br J Cancer 102(9): 1341-1347, 2010. PMID: 20389302. DOI: 10.1038/sj.bjc.6605649

28 Luoma ML, Hakamies-Blomqvist L, Sjostrom J, Pluzanska A, Ottoson S, Mouridsen H, Bengtsson NO, Bergh J, Malmstrom $\mathrm{P}$, Valvere $\mathrm{V}$, Tennvall $\mathrm{L}$ and Blomqvist $\mathrm{C}$ : Prognostic value of quality of life scores for time to progression (TTP) and overall survival time (OS) in advanced breast cancer. Eur J Cancer 39(10): 1370-1376, 2003. PMID: 12826039. DOI: 10.1016/ S0959-8049(02)00775-X

29 Kramer JA, Curran D, Piccart M, de Haes JC, Bruning P, Klijn J, Van Hoorebeeck I and Paridaens R: Identification and interpretation of clinical and quality of life prognostic factors for survival and response to treatment in first-line chemotherapy in advanced breast cancer. Eur J Cancer 36(12): 1498-1506, 2000. PMID: 10930797. DOI: 10.1016/S0959-8049(00)00144-1 